\title{
MOLECULAR INTERACTIONS WITH REFERENCE TO MANIFESTATION OF SOLVATION EFFECTS IN BINARY MIXTURES OF ETHYL ACETOACETATE WITH SOME METHANE DERIVATIVES BY PHYSICOCHEMICAL TECHNIQUES
}

\author{
Mahendra Nath Roy ${ }^{*}$, Lovely Sarkar and Rajani Dewan \\ Department of Chemistry, North Bengal University, Darjeeling 734013, India
}

(Received February 26, 2009; revised July 13, 2009)

\begin{abstract}
Density, $\rho$, viscosity, $\eta$, speed of sound, $u$, and refractive index, $n_{\mathrm{D}}$, were measured for the binary systems of ethyl acetoacetate with dichloromethane, chloroform, carbon tetrachloride, nitromethane, methyl acetate, acetonitrile and acetic acid at $298.15 \mathrm{~K}$ over the entire composition range. From the experimental results, the excess molar volume, $V^{E}$ and the deviation in viscosity, $\Delta \eta$, were calculated. Isentropic compressibility, $k_{\mathrm{S}}{ }^{\mathrm{E}}$, and deviation in molar refractive index, $\Delta R$, were also calculated. These results were fitted to Redlich-Kister polynomial equation. The density and viscosity data were analyzed by some semi-empirical viscosity models, and the results have been discussed in terms of molecular interactions and structural effects. The excess properties were found to be either negative or positive depending on the molecular interactions and the nature of liquid mixtures. To explore the nature of the interactions, various thermodynamic parameters (e.g., intermolecular free length, specific acoustic impedance, etc.) have also been derived from the density and ultrasonic speed data.
\end{abstract}

KEY WORDS: Density, Viscosity, Speed of sound, Isentropic compressibility, Molar refractive index, Ethyl acetoacetate

\section{INTRODUCTION}

The mixing of different solvents gives rise to solutions that generally do not behave ideally. This deviation from ideality is expressed by many thermodynamic variables, particularly by excess properties. Excess thermodynamic properties of solvent mixtures correspond to the difference between the actual property and the property if the system behaves ideally and are useful in the study of molecular interactions and arrangements. In particular, they reflect the interactions that take place between solute-solute, solute-solvent, and solvent-solvent species [1]. This work is a part of our program to provide data for the characterization of the molecular interactions between solvents in binary systems [2, 3]. Having wide usage in flavouring, perfumery, artificial essences, and cosmetics, esters become one of the industrially important classes of liquids. Esters are also used as solvents in pharmaceutical and paint industries and as plasticizers in plastic industries. Among different type of esters, ethyl acetoacetate is commonly used. A fundamental understanding of the mixing behavior of ethyl acetoacetate with common solvents such as dichloromethane, chloroform, carbon tetrachloride, nitromethane, methyl acetate, acetonitrile and acetic acid is therefore important from a technical and engineering viewpoint. The experimental data are used to calculate excess molar volumes, $V^{\mathrm{E}}$, deviations in viscosity, $\Delta \eta$, and deviations in isentropic compressibility, $k_{\mathrm{S}}{ }^{\mathrm{E}}$, of the mixtures. Also, from refractive index data, Lorenz-Lorentz molar refractivity, $\Delta R$, has been computed using mole fraction, $x_{1}$, of ethyl acetoacetate. Various thermodynamic parameters (e.g., intermolecular free length, specific acoustic impedance, etc.) and their deviations have also been derived from the density and ultrasonic speed data. These results are useful for the interpretation of the nature of interactions that occur between solvents. The work also provides a test of various empirical equations to correlate viscosity and acoustic data of binary mixtures in terms of pure component properties.

$\overline{\text { *Correspon }}$ ding author. E-mail: mahendraroy2002@yahoo.co.in 


\section{Materials}

\section{EXPERIMENTAL}

High-purity spectroscopic and analytical grade samples of ethyl acetoacetate, dichloromethane, chloroform, carbon tetrachloride, nitromethane, methyl acetate, acetonitrile and acetic acid were procured from s.d Fine Chemicals Ltd., Mumbai, India. All the samples were used without further purification because their purities exceeded $99 \%$ as tested by gas chromatography (HP 6890 series, Canada) using a flame ionization detector with a packed column. Experimental values of $\rho, \eta, u$ and $n_{\mathrm{D}}$ of the pure liquids are compared in Table 1 at $298.15 \mathrm{~K}$, and these values agree well with the published results. Mixtures were prepared by mass in specially designed glass stopper bottles, and the properties were measured on the same day. An electronic Mettler balance, with a precision of $0.01 \mathrm{mg}$ was used for mass measurements. The error in mole fraction was around 0.0002 .

\section{Apparatus and procedure}

The densities were measured with an Ostwald-Sprengel type pycnometer (Borosil Glass Works Limited, Mumbai) having a bulb volume of $25 \mathrm{~cm}^{3}$ and an internal diameter of the capillary of about $0.1 \mathrm{~cm}$, calibrated at $298.15 \mathrm{~K}$ with doubly distilled water and benzene. The pycnometer with the test solution was equilibrated in a thermostatic water bath maintained at $\pm 0.01 \mathrm{~K}$ of the desired temperature, removed from the bath, properly dried, and weighed in an electronic balance. The evaporation losses remained insignificant during the time of actual measurements. Averages of triplicate measurements were taken into account. The mixtures were prepared by mixing known volume of pure liquids in air-tight stoppered bottles. The reproducibility in mole fraction was within \pm 0.0002 . The mass measurements, accurate to $\pm 0.01 \mathrm{mg}$, were made on a digital electronic analytical balance (Mettler, AG 285, Switzerland). The total uncertainty of density was $\pm 3 \times 10^{-4} \mathrm{~g} . \mathrm{cm}^{-3}$, and that of temperature was $\pm 0.01 \mathrm{~K}$.

The viscosity was measured by means of a suspended Ubbelohde type viscometer (Borosil Glass Works Limited, Mumbai), which was calibrated at $298.15 \mathrm{~K}$ with triple-distilled water and purified methanol using density and viscosity values from the literature. The flow times were accurate to $0.1 \mathrm{~s}$, and the uncertainty in the viscosity measurements, based on our work on several pure liquids, was within $0.03 \%$ of the reported value. Details of the methods and techniques of density and viscosity measurements have been described earlier [4-6].

Speeds of sound were determined by multifrequency ultrasonic interferometer (Mittal Enterprise, New Delhi) working at $1 \mathrm{MHz}$, calibrated with water, methanol, and benzene at $298.15 \mathrm{~K}$. The details of the methods and techniques have been described earlier [4, 5]. The uncertainty of ultrasonic speed measurements is $\pm 0.2 \mathrm{~m} . \mathrm{s}^{-1}$.

The refractive indices of pure liquids and their binary mixture were measured by using a thermostated Abbe refractometer (Atago 3T, Japan). The values of refractive index were obtained using sodium D light. The uncertainty of refractive index measurements was within 0.0001 . The thermostat temperature was constant to $\pm 0.01 \mathrm{~K}$. Water was circulated into the prism of the refractometer by a circulation pump connected to an external thermostated water bath. Calibration was performed by measuring the refractive indices of double-distilled water, toluene, cyclohexane, and carbon tetrachloride at defined temperature. The sample mixtures were directly injected into the prism assembly of the instrument using an airtight hypodermic syringe, and an average of four measurements was taken for each mixture. The reliability of experimental measurements of $n_{\mathrm{D}}$ was ascertained by comparing the experimental data of pure liquids with the corresponding values available in the literature at $298.15 \mathrm{~K}$. 
The solutions were pre-thermostated at $298.15 \mathrm{~K}$ before the experiments to achieve quick thermal equilibrium. A minimum of three independent readings was taken for each composition, and their average value was considered in all of the calculations.

\section{RESULTS AND DISCUSSION}

The physical properties of the pure liquids along with their literature values are recorded in Table 1 [7-16]. Table 2 lists the excess molar volumes, $V^{\mathrm{E}}$ and viscosity deviations, $\Delta \eta$ along with the corresponding mole fractions of ethyl acetoacetate, $x_{1}$. The plots of $V^{\mathrm{E}}$ and $\Delta \eta$ against $x_{1}$ at $298.15 \mathrm{~K}$ are represented in Figures 1 and 2, respectively. The excess molar volumes, $V^{\mathrm{E}}$, were calculated using the equation [17]:

$$
V^{E}=\sum_{i=1}^{j} x_{i} M_{i}\left(1 / \rho-1 / \rho_{i}\right)
$$

where $\rho$ is the mass density of the mixture and $M_{i}, x_{i}$, and $\rho_{i}$, are the molar mass, mole fraction, and density of the $i^{\text {th }}$ component in the mixture, respectively.

Table 1. Comparison of density $\rho$, viscosity $\eta$, sound speeds $\mathrm{u}$ and refractive index $n_{\mathrm{D}}$ with literature data at $298.15 \mathrm{~K}$.

\begin{tabular}{|l|c|c|c|c|c|c|c|c|}
\hline \multirow{2}{*}{ Pure solvent } & \multicolumn{2}{|c|}{$\rho \cdot 10^{-3} /\left(\mathrm{kg} \cdot \mathrm{m}^{-3}\right)$} & \multicolumn{2}{c|}{$\eta /(\mathrm{mPa} \cdot \mathrm{s})$} & \multicolumn{2}{c|}{$u /\left(\mathrm{m} \cdot \mathrm{s}^{-1}\right)$} & \multicolumn{2}{c|}{$n_{\mathrm{D}}$} \\
\cline { 2 - 10 } & Exp. & Lit. & Exp. & Lit. & Exp. & Lit. & Exp. & Lit. \\
\hline Ethylacetoacetate & 1.021 & $1020.8[7]$ & 1.4828 & - & 1331.6 & - & 1.419 & $1.4189[7]$ \\
\hline Dichloromethane & 1.3216 & $1.3161[8]$ & 0.3803 & - & 1035.3 & - & 1.4222 & $1.4212[9]$ \\
\hline Chloroform & 1.4798 & $1.4760[10]$ & 0.498 & - & 985.1 & - & 1.4360 & $1.4432[11]$ \\
\hline Carbon tetrachloride & 1.5874 & $1.5844[12]$ & 0.8258 & - & 917.7 & - & 1.4578 & $1.4574[12]$ \\
\hline Nitromethane & 1.1298 & $1.13042[13]$ & 0.6172 & - & 1317 & $1317.4[13]$ & 1.3929 & - \\
\hline Methylacetate & 0.9273 & $0.92698[14]$ & 0.368 & $0.367[14]$ & 1162.3 & $1151[14]$ & 1.3611 & $1.3586[15]$ \\
\hline Acetonitrile & 0.7772 & $0.7771[16]$ & 0.3435 & $0.390[16]$ & 1282.6 & $1288[16]$ & 1.3419 & $1.3407[16]$ \\
\hline Acetic acid & 1.0431 & $1.04365[14]$ & 1.1296 & $1.115[14]$ & 1132.5 & $1132[14]$ & 1.3700 & - \\
\hline
\end{tabular}

A persual of Table 2 shows that the values of $V^{\mathrm{E}}$ vary for the binary systems with ethyl acetoacetate in the following order:

methyl acetate $>$ carbon tetrachloride $>$ dichloromethane $>$ nitromethane $>$ chloroform $>$ acetic acid $>$ acetonitrile

The largest deviations in $V^{\mathrm{E}}$ are in the range $x_{1}=0.45-0.6$ (Figure 1). The positive values of excess molar volume, $V^{\mathrm{E}}$ for the system ethyl acetoacetate + methyl acetate may be attributed to the dispersion type interactions due to repulsion among the electrons on oxygens. Carbon tetrachloride, dichloromethane and nitromethane interact very weakly with ethyl acetoacetate resulting in positive values of excess molar volume, $V^{\mathrm{E}}$. A similar result for the system ethyl acetoacetate + ethyl acetate was reported earlier [18]. On the contrary the ethyl acetoacetate + chloroform, acetic acid and acetonitrile systems behave rather in a opposite manner. This implies dominance of specific interaction [19] most probably through intermolecular hydrogen bonding between the component liquids, dipole-dipole or dipole-induced dipole interaction [20, $21]$ and also the interstitial accommodation of the mixing components because of the difference in molar volumes [22]. 
Table 2. Values of excess molar volume, $V^{\mathrm{E}}$ and viscosity deviation, $\Delta \eta$.

\begin{tabular}{|c|c|c|c|c|c|}
\hline$x_{1}$ & $V^{\mathrm{E}} \cdot 10^{6} / \mathrm{m}^{3} \mathrm{~mol}^{-1}$ & $\Delta \eta /(\mathrm{mPa} \cdot \mathrm{s})$ & $x_{1}$ & $V^{\mathrm{E}} \cdot 10^{6} / \mathrm{m}^{3} \mathrm{~mol}^{-1}$ & $\Delta \eta /(\mathrm{mPa} \cdot \mathrm{s})$ \\
\hline \multicolumn{3}{|c|}{ Ethylacetoacetate + dichloromethane } & \multicolumn{3}{|c|}{ Ethylacetoacetate + chloroform } \\
\hline 0.0000 & 0.0000 & 0.000 & 0.0000 & 0.0000 & 0.000 \\
\hline 0.0676 & 0.0380 & 0.010 & 0.0925 & -0.1040 & 0.049 \\
\hline 0.1403 & 0.0760 & 0.018 & 0.1865 & -0.1900 & 0.092 \\
\hline 0.2186 & 0.1240 & 0.025 & 0.2822 & -0.2720 & 0.122 \\
\hline 0.3032 & 0.1450 & 0.034 & 0.3795 & -0.3030 & 0.150 \\
\hline 0.3949 & 0.1720 & 0.041 & 0.4784 & -0.3030 & 0.168 \\
\hline 0.4947 & 0.1770 & 0.047 & 0.5791 & -0.2620 & 0.171 \\
\hline 0.6036 & 0.1560 & 0.046 & 0.6816 & -0.1900 & 0.156 \\
\hline 0.7230 & 0.1090 & 0.034 & 0.7858 & -0.1180 & 0.117 \\
\hline 0.8545 & 0.0530 & 0.016 & 0.8920 & -0.0520 & 0.068 \\
\hline 1.0000 & 0.0000 & 0.000 & 1.0000 & 0.0000 & 0.000 \\
\hline \multicolumn{3}{|c|}{ Ethylacetoacetate + carbontetrachloride } & \multicolumn{3}{|c|}{ Ethylacetoacetate + nitromethane } \\
\hline 0.0000 & 0.0000 & 0.000 & 0.0000 & 0.0000 & 0.000 \\
\hline 0.1161 & 0.1780 & 0.007 & 0.0495 & 0.0200 & 0.010 \\
\hline 0.2281 & 0.3180 & 0.015 & 0.1050 & 0.0570 & 0.024 \\
\hline 0.3362 & 0.4450 & 0.021 & 0.1674 & 0.0790 & 0.039 \\
\hline 0.4407 & 0.5150 & 0.025 & 0.2382 & 0.0930 & 0.052 \\
\hline 0.5417 & 0.5140 & 0.027 & 0.3193 & 0.1050 & 0.065 \\
\hline 0.6394 & 0.4090 & 0.023 & 0.4130 & 0.0960 & 0.075 \\
\hline 0.7339 & 0.3020 & 0.016 & 0.5225 & 0.0950 & 0.081 \\
\hline 0.8254 & 0.1850 & 0.009 & 0.6523 & 0.0640 & 0.073 \\
\hline 0.9141 & 0.0790 & 0.005 & 0.8085 & 0.0470 & 0.046 \\
\hline 1.0000 & 0.0000 & 0.000 & 1.0000 & 0.0000 & 0.000 \\
\hline \multicolumn{3}{|c|}{ Ethylacetoacetate + methylacetate } & \multicolumn{3}{|c|}{ Ethylacetoacetate + acetonitrile } \\
\hline 0.0000 & 0.0000 & 0.000 & 0.0000 & 0.0000 & 0.000 \\
\hline 0.0595 & 0.2210 & -0.005 & 0.0339 & -0.0670 & 0.001 \\
\hline 0.1246 & 0.4330 & -0.027 & 0.0731 & -0.1580 & -0.006 \\
\hline 0.1961 & 0.6270 & -0.044 & 0.1191 & -0.2730 & -0.012 \\
\hline 0.2751 & 0.7830 & -0.069 & 0.1737 & -0.3760 & -0.020 \\
\hline 0.3627 & 0.9380 & -0.089 & 0.2398 & -0.5030 & -0.027 \\
\hline 0.4606 & 1.0310 & -0.104 & 0.3212 & -0.6320 & -0.038 \\
\hline 0.5705 & 0.9770 & -0.113 & 0.4240 & -0.7900 & -0.047 \\
\hline 0.6948 & 0.7700 & -0.109 & 0.5579 & -0.8640 & -0.055 \\
\hline 0.8367 & 0.4020 & -0.080 & 0.7395 & -0.7000 & -0.045 \\
\hline 1.0000 & 0.0000 & 0.000 & 1.0000 & 0.0000 & 0.000 \\
\hline
\end{tabular}

Ethylacetoacetate + acetic acid

\begin{tabular}{|l|l|l|}
\hline 0.0000 & 0.0000 & 0.000 \\
\hline 0.0488 & -0.0790 & 0.045 \\
\hline 0.1034 & -0.1550 & 0.079 \\
\hline 0.1651 & -0.2410 & 0.119 \\
\hline 0.2353 & -0.3180 & 0.155 \\
\hline 0.3157 & -0.3810 & 0.191 \\
\hline 0.4090 & -0.4550 & 0.220 \\
\hline 0.5185 & -0.5060 & 0.241 \\
\hline 0.6486 & -0.4650 & 0.235 \\
\hline 0.8059 & -0.2920 & 0.167 \\
\hline 1.0000 & 0.0000 & 0.000 \\
\hline
\end{tabular}

Bull. Chem. Soc. Ethiop. 2010, 24(1) 


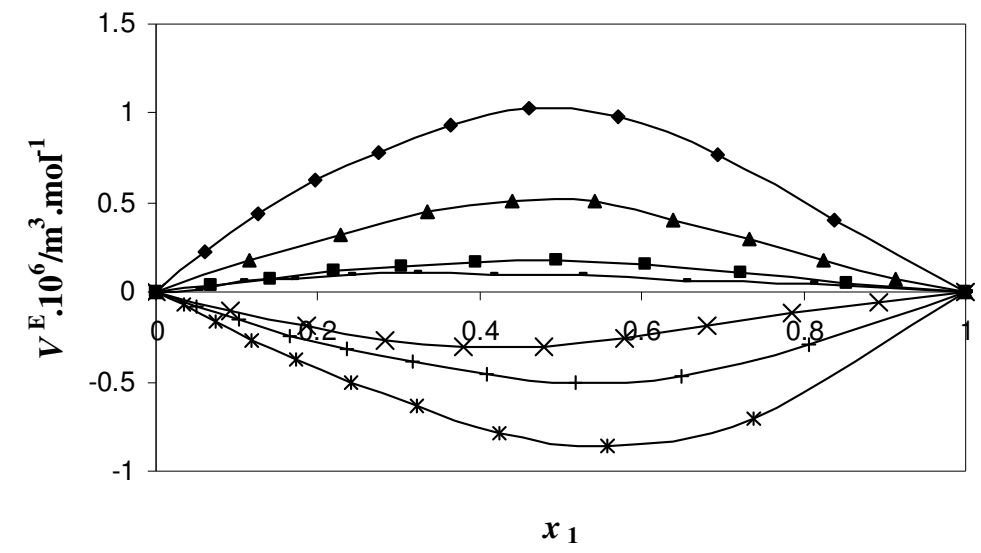

Figure 1. Excess molar volumes $\left(V^{\mathrm{E}}\right)$ for binary mixtures of ethyl acetoacetate (1) with dichloromethane $(\boldsymbol{\square})$, chloroform $(\mathbf{x})$, carbon tetrachloride $(\mathbf{\Delta})$, nitromethane (-), methyl acetate $(\bullet)$, acetonitrile $(*)$ and acetic acid $(+)$.

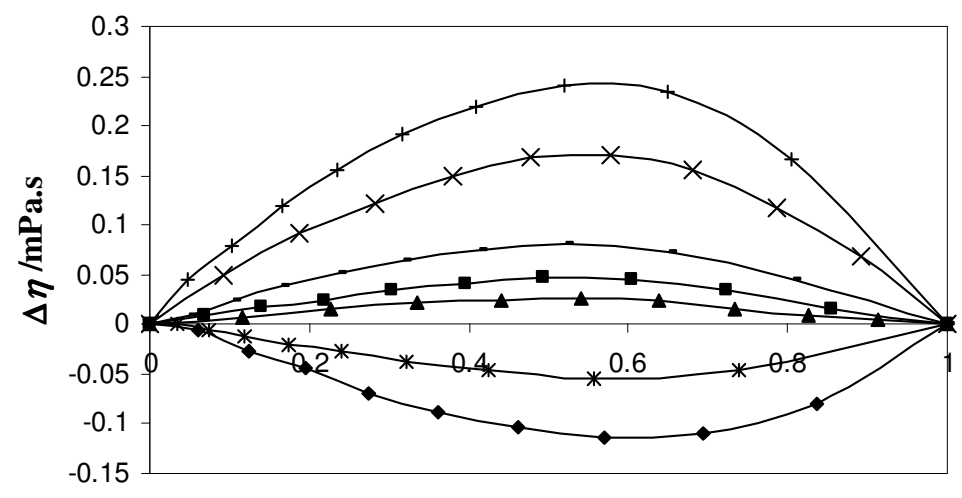

$x_{1}$

Figure 2. Viscosity deviations $(\Delta \eta)$ for binary mixtures of ethyl acetoacetate (1) with dichloromethane $(\mathbf{\square})$, chloroform $(\times)$, carbon tetrachloride $(\boldsymbol{\Delta})$, nitromethane $(-)$, methyl acetate $(\bullet)$, acetonitrile $(*)$ and acetic acid $(+)$.

The deviation in viscosities, $\Delta \eta$ can be computed using the equation [23, 24]:

$$
\Delta \eta=\eta-\sum_{i=1}^{j}\left(x_{i} \eta_{i}\right)
$$

where $\eta$ is the dynamic viscosity of the mixture and $x_{i}$ and $\eta_{i}$ are the mole fraction and viscosity of the $i^{\text {th }}$ component in the mixture, respectively.

As far as $\Delta \eta$ values are concerned, the experimental binary mixtures exhibit positive as well as negative values over the entire composition range at the experimental temperature. The maxima and minima of the curves lie within mole fraction $x_{1}=0.45-0.65$. According to Fort and 
Moore [17] excess viscosities are negative in mixtures of components having unequal size and in which dispersion forces are present. The positive values of $\Delta \eta$ increase for the seven systems with ethyl acetoacetate are in the following sequence:

methyl acetate $<$ acetonitrile $<$ carbon tetrachloride $<$ dichloromethane $<$ nitromethane $<$ chloroform <acetic acid

The positive $\Delta \eta$ values indicate specific interaction and its negative values indicate dominance of disruption forces. Thus the order of $\Delta \eta$ values (Figure 2) supports our earlier results obtained from $V^{\mathrm{E}}$ values.

Isentropic compressibilities, $k_{\mathrm{S}}$, the deviations in isentropic compressibilities, $k_{\mathrm{S}}^{\mathrm{E}}$, deviations in intermolecular, free length, $\Delta L_{\mathrm{f}}$ and deviations in specific acoustic impedance, $\Delta Z$, are calculated from the experimental densities, $\rho$, speeds of sound, $u$, intermolecular free length, $L_{\mathrm{f}}$, and specific acoustic impedance, $Z$ of the mixture using the required equations [25-27].

Experimental values of $u, k_{\mathrm{S}}, k_{\mathrm{S}}^{\mathrm{E}}, \Delta L_{\mathrm{f}}$, and $\Delta Z$ are listed in Table 3, and the plots of $k_{\mathrm{S}}{ }^{\mathrm{E}}, \Delta L_{\mathrm{f}}$, and $\Delta Z$ against $x_{1}$ are shown in Figures 3 to 5 . For the investigated binary mixtures, the deviations in isentropic compressibility are just parallel to that of $V^{\mathrm{E}}$. The composition dependence of $k_{\mathrm{S}}^{\mathrm{E}}$ for the investigated binary mixtures is shown in Figure 3; it shows that $k_{\mathrm{S}}^{\mathrm{E}}$ values for the binary systems with ethyl acetoacetate decrease in the following order:

methyl acetate $>$ carbontetrachloride $>$ dichloromethane $>$ nitromethane $>$ chloroform $>$ acetic acid $>$ acetonitrile.

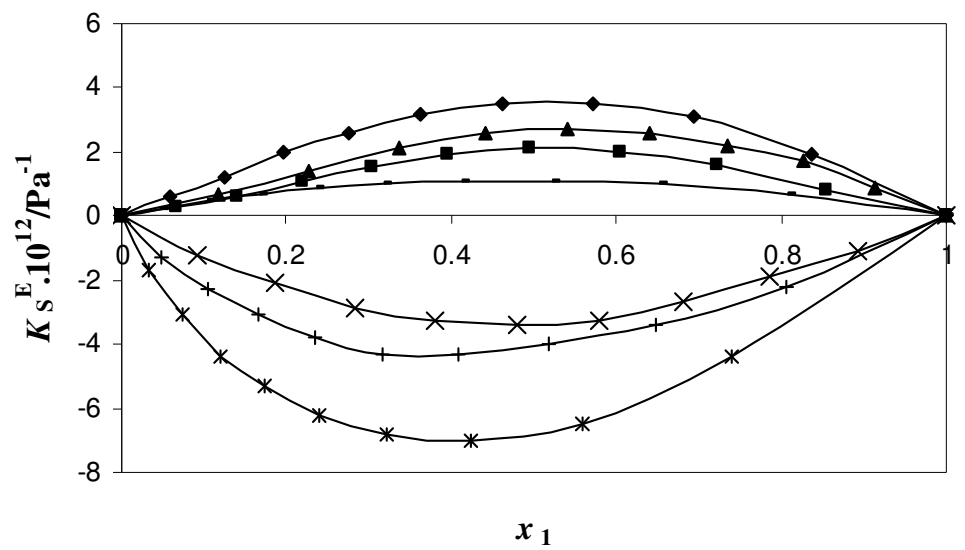

Figure 3. Deviations in isentropic compressibility $\left(k_{S}^{\mathrm{E}}\right)$ for binary mixtures of ethyl acetoacetate (1) with dichloromethane $(\boldsymbol{\square})$, chloroform $(\times)$, carbon tetrachloride $(\boldsymbol{\Delta})$, nitromethane $(-)$, methyl acetate $(\bullet)$, acetonitrile $(*)$ and acetic acid $(+)$.

These results can be explained in terms of molecular interactions and structural effects. Figures 4 and 5 illustrate that $\Delta L_{\mathrm{f}}$ values are opposite to $\Delta Z$. Positive and negative deviations in these functions from linear dependence on composition of the mixtures indicate the extent of association or dissociation between the mixing components [28]. The observed values of $k_{\mathrm{S}}{ }^{\mathrm{E}}$ and $\Delta L_{\mathrm{f}}$ can be qualitatively explained by considering the following factors: (i) the mutual disruption of associates present in pure liquids, (ii) dipole-induced interaction between the mixing liquids, and (iii) interstitial accommodation [29] of one component into another. Thus the graded behaviors of these functions support the results obtained earlier. 
Table 3. Values of ultrasonic speeds $u$, deviations in isentropic compressibility $k_{\mathrm{S}}{ }^{\mathrm{E}}$, deviations in intermolecular free length $\left(\Delta L_{\mathrm{f}}\right)$, and deviations in specific acoustic impedance $(\Delta Z)$ for binary mixtures at $298.15 \mathrm{~K}$.

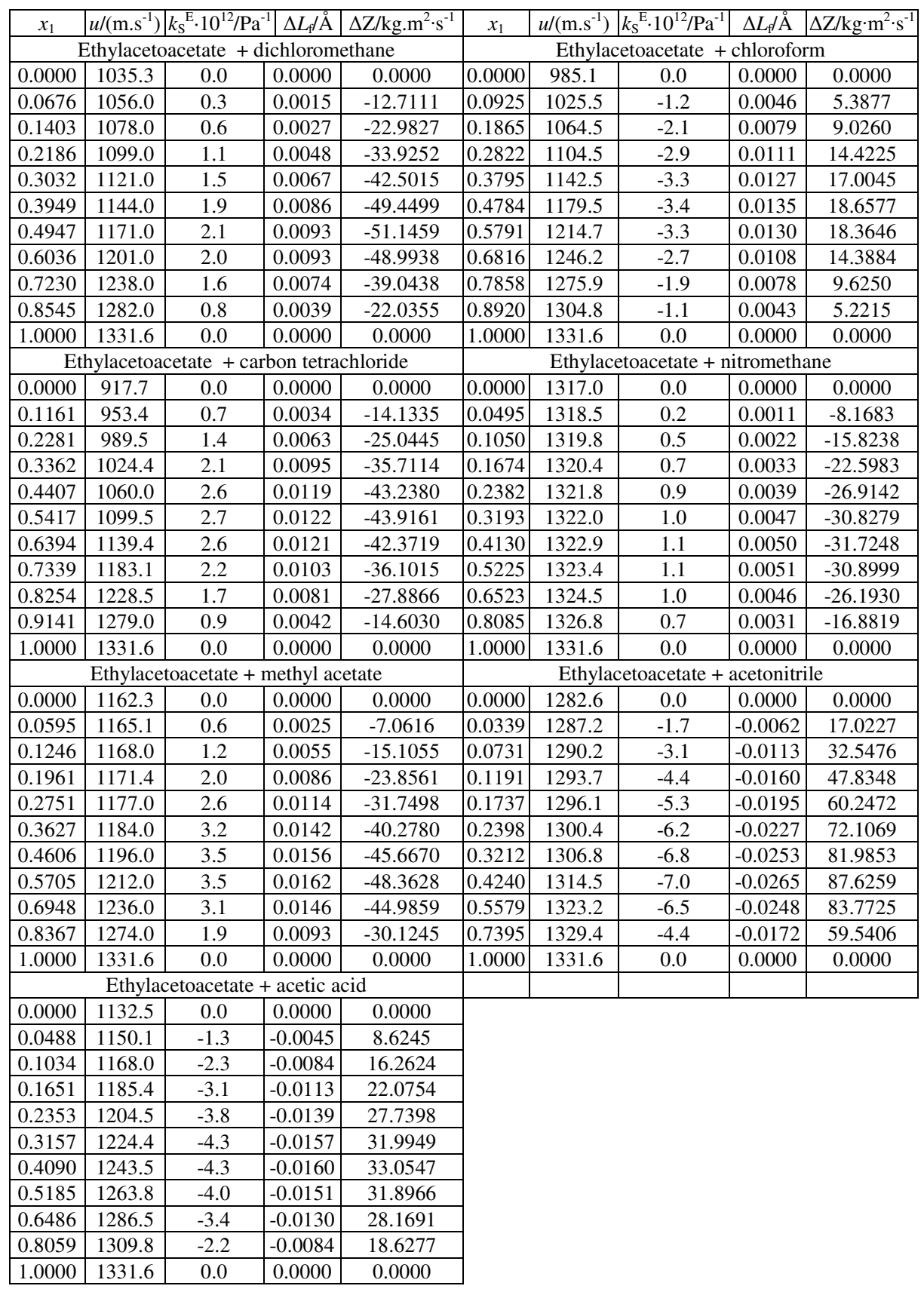

Bull. Chem. Soc. Ethiop. 2010, 24(1) 


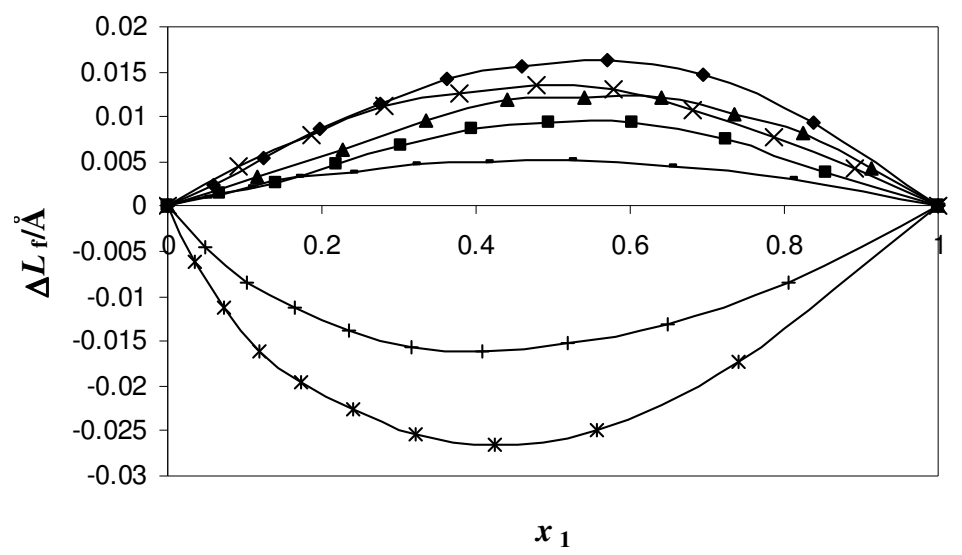

Figure 4. Deviations in intermolecular free length $\left(\Delta L_{\mathrm{f}}\right)$ for binary mixtures of ethyl acetoacetate (1) with dichloromethane $(\boldsymbol{\bullet})$, chloroform $(\times)$, carbon tetrachloride $(\mathbf{\Delta})$, nitromethane $(-)$, methyl acetate $(\bullet)$, acetonitrile $(*)$ and acetic acid $(+)$.

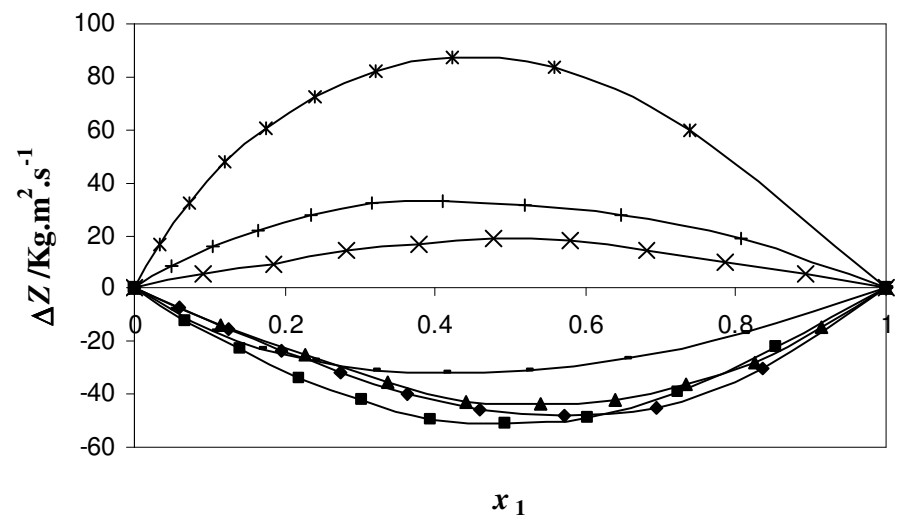

Figure 5. Deviations in specific acoustic impedance $(\Delta Z)$ for binary mixtures of ethyl acetoacetate (1) with dichloromethane $(\boldsymbol{\square})$, chloroform $(\times)$, carbon tetrachloride $(\boldsymbol{\Delta})$, nitromethane $(-)$, methyl acetate $(\bullet)$, acetonitrile $(*)$ and acetic acid $(+)$.

Table 4 represents the experimental refractive index, molar refractivity by Lorentz-Lorenz Equation and deviation in molar refractivity at $298.15 \mathrm{~K}$. The molar refractions, $R$, which were calculated using the Lorentz-Lorenz equation [30]

$$
R=\left(n_{\mathrm{D}}^{2}-1 / n_{\mathrm{D}}^{2}+2\right) V
$$

where $n_{\mathrm{D}}$ and $V$ being the refractive index and the molar volume, respectively; and $\Delta R$ the molar refraction changes of mixing, which were obtained from the following equation.

$$
\Delta R=R-\sum_{i=1}^{j}\left(x_{i} R_{i}\right)
$$


where $R$ is the molar refraction of the mixture and $x_{i}$ and $R_{i}$ are the mole fraction and molar refraction of the $i^{\text {th }}$ component in the mixture, respectively. The dependence of molar refraction, $\Delta R$ on mole fraction, $x_{1}$, of ethyl acetoacetate at $298.15 \mathrm{~K}$ is displayed in Figure 6. It is observed that, for all the mixtures $\Delta R$ contains both positive and negative values. It may be attributed to the electronic perturbation of the individual molecules during mixing and, therefore, depends on the nature of the mixing molecules and only on the wavelength of the light used for measurement [31]. The positive $\Delta R$ values vary in the order:

methyl acetate $<$ carbon tetrachloride $<$ dichloromethane $<$ nitromethane $<$ chloroform $<$ acetic acid $<$ acetonitrile.

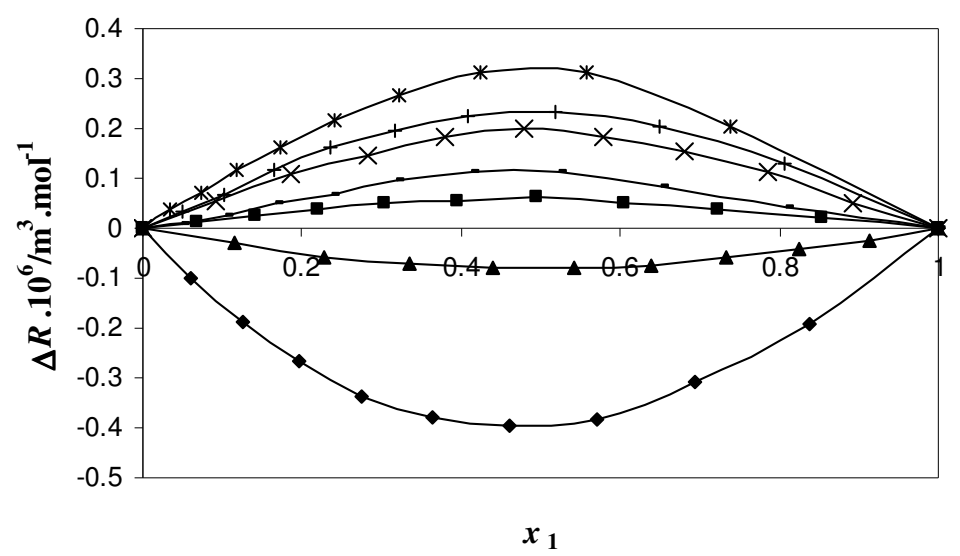

Figure 6. Deviations in molar refractive index $(\Delta R)$ for binary mixtures of ethyl acetoacetate (1) with dichloromethane $(\boldsymbol{\square})$, chloroform $(\times)$, carbon tetrachloride $(\boldsymbol{\Delta})$, nitromethane $(-)$, methyl acetate $(\bullet)$, acetonitrile $(*)$ and acetic acid $(+)$.

For each mixture, the mixing functions $V^{\mathrm{E}}, \Delta \eta, K_{\mathrm{S}}^{\mathrm{E}}, \Delta L_{\mathrm{f}}, \Delta Z$ and $\Delta R$ were fitted to a RedlichKister polynomial regression [32] of the type

$$
Y^{E}{ }_{i j}=x_{i} x_{j} \sum_{k=1}^{m} A_{k}\left(x_{i}-x_{j}\right)^{k}
$$

where $Y^{E}{ }_{i j}$ refers to an excess property $\left(V^{\mathrm{E}}, \Delta \eta, K_{\mathrm{S}}^{\mathrm{E}}, \Delta L_{\mathrm{f}}, \Delta Z, \Delta R\right)$ for each $i-j$ binary pair, and $x_{i}$ is the mole fraction of $i$ th component, and $A_{k}$ represents the coefficients.

The values of coefficients $A_{k}$ of equation (5) and the corresponding standard deviations, $\sigma$ obtained by the method of least squares with equal weights assigned to each point are calculated. The standard deviations $(\sigma)$ are defined as:

$$
\sigma=\left[\left(Y_{\text {exp }}^{E}-Y_{\text {cal }}^{E}\right)^{2} /(n-m)\right]^{1 / 2}
$$

where $n$ represents the number of measurements and $m$ the number of coefficients. The values of coefficients $\left(A_{k}\right)$ is determined by a multiple-regression analysis based on the least square method and summarized along with the standard deviations between the experimental and fitted values of, $V^{E}, \Delta \eta, K_{\mathrm{S}}^{\mathrm{E}}, \Delta L_{f}, \Delta Z, \Delta R$ are presented in Table 5. Finally, it can be concluded that the expressions used for interpolating the experimental data measured in this work gave good results, as can be seen by inspecting the $\sigma$ values obtained. 
Table 4. Experimental and calculated values of refractive index, $n_{\mathrm{D}}$, and deviation in molar refraction $\Delta R$ of binary mixtures at $298.15 \mathrm{~K}$.

\begin{tabular}{|c|c|c|c|c|c|}
\hline$x_{1}$ & $n_{\mathrm{D}}$ & $\Delta R \times 10^{6} / \mathrm{m}^{3} \mathrm{~mol}^{-1}$ & $x_{1}$ & $n_{D}$ & $\Delta R \times 10^{6} / \mathrm{m}^{3} \mathrm{~mol}^{-1}$ \\
\hline \multicolumn{3}{|c|}{ Ethylacetoacetate + dichloromethane } & \multicolumn{3}{|c|}{ Ethylacetoacetate + chloroform } \\
\hline 0.0000 & 1.4222 & 0.0000 & 0.0000 & 1.436 & 0.0000 \\
\hline 0.0676 & 1.4219 & 0.0133 & 0.0925 & 1.4355 & 0.0559 \\
\hline 0.1403 & 1.4216 & 0.0263 & 0.1865 & 1.4348 & 0.1066 \\
\hline 0.2186 & 1.4212 & 0.0374 & 0.2822 & 1.4339 & 0.1473 \\
\hline 0.3032 & 1.421 & 0.0492 & 0.3795 & 1.4327 & 0.1835 \\
\hline 0.3949 & 1.4206 & 0.0532 & 0.4784 & 1.4311 & 0.2019 \\
\hline 0.4947 & 1.4204 & 0.0607 & 0.5791 & 1.4288 & 0.1854 \\
\hline 0.6036 & 1.4200 & 0.0507 & 0.6816 & 1.4263 & 0.155 \\
\hline 0.723 & 1.4197 & 0.0383 & 0.7858 & 1.4238 & 0.1131 \\
\hline 0.8545 & 1.4194 & 0.0225 & 0.892 & 1.4212 & 0.0513 \\
\hline 1.0000 & 1.4190 & 0.0000 & 1.0000 & 1.4190 & 0.0000 \\
\hline \multicolumn{3}{|c|}{ Ethylacetoacetate + carbontetrachloride } & \multicolumn{3}{|c|}{ Ethylacetoacetate + nitromethane } \\
\hline 0.0000 & 1.4578 & 0.0000 & 0.0000 & 1.3929 & 0.0000 \\
\hline 0.1161 & 1.4505 & -0.0308 & 0.0495 & 1.3958 & 0.0070 \\
\hline 0.2281 & 1.4442 & -0.0572 & 0.105 & 1.3989 & 0.0264 \\
\hline 0.3362 & 1.4388 & -0.0701 & 0.1674 & 1.4021 & 0.0495 \\
\hline 0.4407 & 1.4342 & -0.0802 & 0.2382 & 1.4051 & 0.0679 \\
\hline 0.5417 & 1.4305 & -0.0785 & 0.3193 & 1.4082 & 0.0939 \\
\hline 0.6394 & 1.4276 & -0.0739 & 0.413 & 1.4111 & 0.1121 \\
\hline 0.7339 & 1.4251 & -0.0603 & 0.5225 & 1.4135 & 0.1137 \\
\hline 0.8254 & 1.4229 & -0.0436 & 0.6523 & 1.4154 & 0.0833 \\
\hline 0.9141 & 1.4209 & -0.0232 & 0.8085 & 1.4171 & 0.0419 \\
\hline 1.0000 & 1.4190 & 0.0000 & 1.0000 & 1.4190 & 0.0000 \\
\hline \multicolumn{3}{|c|}{ Ethylacetoacetate + methylacetate } & \multicolumn{3}{|c|}{ Ethylacetoacetate + acetonitrile } \\
\hline 0.0000 & 1.3611 & 0.0000 & 0.0000 & 1.3419 & 0.0000 \\
\hline 0.0595 & 1.3630 & -0.1014 & 0.0339 & 1.3494 & 0.0355 \\
\hline 0.1246 & 1.3656 & -0.1870 & 0.0731 & 1.3573 & 0.0729 \\
\hline 0.1961 & 1.3687 & -0.2672 & 0.1191 & 1.3657 & 0.1154 \\
\hline 0.2751 & 1.3725 & -0.336 & 0.1737 & 1.3743 & 0.1622 \\
\hline 0.3627 & 1.3771 & -0.3775 & 0.2398 & 1.3834 & 0.216 \\
\hline 0.4606 & 1.3826 & -0.3978 & 0.3212 & 1.3925 & 0.2646 \\
\hline 0.5705 & 1.3895 & -0.3834 & 0.424 & 1.4019 & 0.3132 \\
\hline 0.6948 & 1.3981 & -0.3096 & 0.5579 & 1.4100 & 0.3127 \\
\hline 0.8367 & 1.408 & -0.1919 & 0.7395 & 1.4156 & 0.2062 \\
\hline 1.0000 & 1.419 & 0.0000 & 1.0000 & 1.4190 & 0.0000 \\
\hline \multicolumn{3}{|c|}{ Ethylacetoacetate + acetic acid } & & & \\
\hline 0.0000 & 1.3700 & 0.0000 & & & \\
\hline 0.0488 & 1.3765 & 0.0342 & & & \\
\hline 0.1034 & 1.3828 & 0.0681 & & & \\
\hline 0.1651 & 1.3894 & 0.1168 & & & \\
\hline 0.2353 & 1.3956 & 0.1607 & & & \\
\hline 0.3157 & 1.4013 & 0.1956 & & & \\
\hline 0.409 & 1.4068 & 0.2264 & & & \\
\hline 0.5185 & 1.4115 & 0.2318 & & & \\
\hline 0.6486 & 1.4151 & 0.2041 & & & \\
\hline 0.8059 & 1.4175 & 0.1305 & & & \\
\hline 1.0000 & 1.4190 & 0.0000 & & & \\
\hline
\end{tabular}

Bull. Chem. Soc. Ethiop. 2010, 24(1) 
Table 5. Redlich-Kister coefficients $A_{\mathrm{k}}$ and standard deviations $\sigma$ for the binary mixtures.

\begin{tabular}{|c|c|c|c|c|c|c|}
\hline Excess property & $A_{0}$ & $A_{1}$ & $A_{2}$ & $A_{3}$ & $A_{4}$ & $\sigma$ \\
\hline \multicolumn{7}{|c|}{ Ethylacetoacetate + dichloromethane } \\
\hline$V^{E} \times 10^{6} /\left(\mathrm{m}^{3} \mathrm{~mol}^{-1}\right)$ & 0.6977 & -0.1688 & -0.3257 & & & 0.0039 \\
\hline$\Delta \eta /(\mathrm{mPa} . \mathrm{s})$ & 0.1882 & 0.0388 & -0.1411 & -0.1018 & 0.0803 & 0.0009 \\
\hline$k_{\mathrm{S}}^{\mathrm{E}} \times 10^{12} /\left(\mathrm{Pa}^{-1}\right)$ & 8.3903 & 1.3339 & -4.9019 & -1.1154 & & 0.0294 \\
\hline$\Delta R \times 10^{6} /\left(\mathrm{m}^{3} \mathrm{~mol}^{-1}\right)$ & 0.2276 & -0.0331 & -0.0690 & & & 0.0021 \\
\hline$\Delta L_{\mathrm{f}} / \AA$ & 0.0378 & 0.0062 & -0.0192 & & & 0.0002 \\
\hline$\Delta \mathrm{Z} / \mathrm{kg} \cdot \mathrm{m}^{2} \cdot \mathrm{s}^{-1}$ & -206.1949 & 1.1140 & 40.3622 & 23.7161 & & 0.4708 \\
\hline \multicolumn{7}{|c|}{ Ethylacetoacetate + chloroform } \\
\hline$V^{E} \times 10^{6} /\left(\mathrm{m}^{3} \mathrm{~mol}^{-1}\right)$ & -1.1876 & 0.6416 & 0.7055 & -0.3396 & -0.3519 & 0.0041 \\
\hline$\Delta \eta /($ mPa.s $)$ & 0.6767 & 0.1454 & -0.0686 & -0.1446 & & 0.0021 \\
\hline$k_{\mathrm{S}}^{\mathrm{E}} \times 10^{12} /\left(\mathrm{Pa}^{-1}\right)$ & -13.6407 & 2.1562 & 2.1469 & & & 0.0593 \\
\hline$\Delta R \times 10^{6} /\left(\mathrm{m}^{3} \mathrm{~mol}^{-1}\right)$ & 0.7853 & -0.0551 & -0.3069 & & & 0.0038 \\
\hline$\Delta L_{\mathrm{f}} / \AA$ & -0.0537 & 0.0058 & 0.0096 & & & 0.0002 \\
\hline$\Delta \mathrm{Z} / \mathrm{kg} \cdot \mathrm{m}^{2} \cdot \mathrm{s}^{-1}$ & 74.3049 & -5.1560 & -34.4113 & & & 0.6037 \\
\hline \multicolumn{7}{|c|}{ Ethylacetoacetate + carbon tetrachloride } \\
\hline$V^{E} \times 10^{6} /\left(\mathrm{m}^{3} \mathrm{~mol}^{-1}\right)$ & 2.0336 & -0.3775 & -1.2170 & & & 0.0139 \\
\hline$\Delta \eta /(\mathrm{mPa} . \mathrm{s})$ & 0.1042 & -0.0046 & -0.0756 & & & 0.0011 \\
\hline$k_{\mathrm{S}}^{\mathrm{E}} \times 10^{12} /\left(\mathrm{Pa}^{-1}\right)$ & 10.7064 & 3.0685 & -2.8537 & & & 0.0423 \\
\hline$\Delta R \times 10^{6} /\left(\mathrm{m}^{3} \mathrm{~mol}^{-1}\right)$ & -0.3211 & 0.0076 & 0.0309 & & & 0.0012 \\
\hline$\Delta L_{\mathrm{f}} / \AA$ & 0.0488 & 0.0154 & -0.0100 & & & 0.0003 \\
\hline$\Delta \mathrm{Z} / \mathrm{kg} \cdot \mathrm{m}^{2} \cdot \mathrm{s}^{-1}$ & -175.7724 & -37.5399 & 26.7914 & & & 0.7621 \\
\hline \multicolumn{7}{|c|}{ Ethylacetoacetate + nitromethane } \\
\hline$V^{E} \times 10^{6} /\left(\mathrm{m}^{3} \mathrm{~mol}^{-1}\right)$ & 0.3658 & -0.2896 & 0.1431 & 0.2418 & & 0.0057 \\
\hline$\Delta \eta /(\mathrm{mPa} . \mathrm{s})$ & 0.3190 & 0.0202 & -0.0850 & & & 0.0009 \\
\hline$k_{\mathrm{S}}^{\mathrm{E}} \times 10^{12} /\left(\mathrm{Pa}^{-1}\right)$ & 4.4471 & -0.3546 & 0.7162 & & & 0.0248 \\
\hline$\Delta R \times 10^{6} /\left(\mathrm{m}^{3} \mathrm{~mol}^{-1}\right)$ & 0.4518 & -0.0849 & -0.3876 & & & 0.0033 \\
\hline$\Delta L_{\mathrm{f}} / \AA$ & 0.0208 & -0.0023 & & & & 0.0001 \\
\hline$\Delta \mathrm{Z} / \mathrm{kg} \cdot \mathrm{m}^{2} \cdot \mathrm{s}^{-1}$ & -124.7042 & 37.7423 & -21.6414 & & & 0.2729 \\
\hline \multicolumn{7}{|c|}{ Ethylacetoacetate + methylacetate } \\
\hline$V^{E} \times 10^{6} /\left(\mathrm{m}^{3} \mathrm{~mol}^{-1}\right)$ & 4.0965 & -0.3689 & -1.9771 & -0.7811 & 1.0977 & 0.0097 \\
\hline$\Delta \eta /(\mathrm{mPa} . \mathrm{s})$ & -0.4312 & -0.1777 & -0.0648 & -0.1381 & 0.1718 & 0.0021 \\
\hline$k_{\mathrm{S}}^{\mathrm{E}} \times 10^{12} /\left(\mathrm{Pa}^{-1}\right)$ & 14.3078 & 1.4510 & -2.9081 & & & 0.0446 \\
\hline$\Delta R \times 10^{6} /\left(\mathrm{m}^{3} \mathrm{~mol}^{-1}\right)$ & -1.5823 & 0.2385 & 0.0620 & & & 0.0033 \\
\hline$\Delta L_{\mathrm{f}} / \AA$ & 0.0647 & 0.0121 & -0.0091 & & & 0.0002 \\
\hline$\Delta \mathrm{Z} / \mathrm{kg} \cdot \mathrm{m}^{2} \cdot \mathrm{s}^{-1}$ & -189.7685 & -57.8767 & 13.8619 & & & 0.3351 \\
\hline \multicolumn{7}{|c|}{ Ethylacetoacetate + acetonitrile } \\
\hline$V^{E} \times 10^{6} /\left(\mathrm{m}^{3} \mathrm{~mol}^{-1}\right)$ & -3.3898 & -1.0626 & 0.7564 & 0.8072 & & 0.0097 \\
\hline$\Delta \eta /(\mathrm{mPa} . \mathrm{s})$ & -0.2104 & -0.0772 & 0.0707 & & & 0.0017 \\
\hline$k_{\mathrm{S}}^{\mathrm{E}} \times 10^{12} /\left(\mathrm{Pa}^{-1}\right)$ & -27.3834 & 9.1231 & 0.8057 & 6.5558 & -4.0858 & 0.0494 \\
\hline$\Delta R \times 10^{6} /\left(\mathrm{m}^{3} \mathrm{~mol}^{-1}\right)$ & 1.2839 & -0.0260 & -0.6748 & -0.4276 & & \begin{tabular}{|l}
0.0018 \\
\end{tabular} \\
\hline$\Delta L_{\mathrm{f}} / \AA$ & -0.1042 & 0.0307 & 0.0094 & 0.0143 & -0.0678 & 0.0001 \\
\hline$\Delta \mathrm{Z} / \mathrm{kg} \cdot \mathrm{m}^{2} \cdot \mathrm{s}^{-1}$ & 348.1667 & -70.6471 & -16.1459 & -59.8619 & 95.3339 & 0.3146 \\
\hline \multicolumn{7}{|c|}{ Ethylacetoacetate + acetic acid } \\
\hline$V^{E} \times 10^{6} /\left(\mathrm{m}^{3} \mathrm{~mol}^{-1}\right)$ & -1.9880 & -0.4359 & 0.5301 & 0.8299 & & 0.0064 \\
\hline$\Delta \eta /$ (mPa.s) & 0.9580 & 0.2553 & 0.0183 & -0.2208 & & 0.0016 \\
\hline$k_{\mathrm{S}}^{\mathrm{E}} \times 10^{12} /\left(\mathrm{Pa}^{-1}\right)$ & -16.4179 & 6.7081 & -4.7127 & & & 0.0592 \\
\hline$\Delta R \times 10^{6} /\left(\mathrm{m}^{3} \mathrm{~mol}^{-1}\right)$ & 0.9309 & -0.0655 & -0.2292 & 0.1317 & & 0.0025 \\
\hline$\Delta L_{\mathrm{f}} / \AA$ & -0.0617 & 0.0220 & -0.0156 & & & 0.0002 \\
\hline$\Delta \mathrm{Z} / \mathrm{kg} \cdot \mathrm{m}^{2} \cdot \mathrm{s}^{-1}$ & 130.1334 & -33.0719 & 25.7843 & & & 0.3620 \\
\hline
\end{tabular}




\section{CONCLUSIONS}

It is realized that these binary data will have some relevance in industries because the esters are known to act as plasticizing agents for many industrial plastics. Furthermore, the structural changes and the appearance of dispersion forces and further hetero associations by mixing with ethyl acetoacetate make these systems particularly interesting. The interaction parameters deduced can be used to further predict these properties in multi-component mixtures.

\section{AKNOWLEDGEMENTS}

The authors are grateful to the Departmental Special Assistance Scheme under the University Grants Commission, New Delhi (No. 540/6/DRS/2002, SAP-1) for financial support. One of the authors is also grateful to UGC Research Fellowship in Science Ref. UGC letter No. F.4 -1 /2006 (X1 plan /BSR) for sanctioning a Junior Research Fellowship and providing financial aid in support of this research work.

\section{REFERENCES}

1. Kim, E.S.; Marsh, K.N. J. Chem. Eng. Data 1988, 33, 288.

2. Roy, M.N.; Sinha, B.; Dakua, V.K. J. Chem. Eng. Data 2006, 51, 590.

3. Roy, M.N.; Sinha, A.; Sinha, B. J. Solution Chem. 2005, 34, 1311.

4. Roy, M.N.; Jha, A.; Dey, R. J. Chem. Eng. Data 2001, 46, 1327.

5. Roy, M.N.; Hazra, D.K. Indian J. Chem. Technol. 1994, $1,93$.

6. Roy, M.N.; Jha, A.; Choudhury, A. J. Chem. Eng. Data 2004, 49, 291.

7. Nayak, J.N.; Aralaguppi, M.I.; Aminabhavi, T.M. J. Chem. Eng. Data 2003, 48, 1489.

8. Comelli, F.; Francesconi, R. J. Chem. Eng. Data 1995, 40, 509.

9. Zurita, J.L.; Soria, M.L.G.; Postigo, M.A.; Katz, M. J. Chem. Eng. Data 1986, 31, 389.

10. Asfour, A.F.A.; Dullien, F.A.L. J. Chem. Eng. Data 1981, 26, 312.

11. Aminabhavi, T.M.; Patil, V.B. J. Chem. Eng. Data 1998, 43, 497.

12. Riddick, J.A.; Bunger, W.B.; Sakano, T.K. Techniques of Chemistry, Organic Solvents, Physical Properties and Methods of Purification, Vol. II, John Wiley and Sons: New York; 1986.

13. Makowska, A.; Szydłowski, J. J. Chem. Eng. Data 2005, 50, 1365.

14. González, B.; Domínguez, A.; Tojo J. J. Chem. Eng. Data 2004, 49, 1590.

15. Aminabhavi, T.M.; Raikar, S.K.; Balundgi, R.H. J. Chem. Eng. Data 1993, 38, 441.

16. Jadar C.V., Aminabhavi, T.M. J. Chem. Eng. Data 1996, 41, 1307.

17. Fort, R.J.; Moore, W.R. Trans. Faraday Soc. 1966, 62, 1112.

18. Hui, G.; Yihe, W.; Weidong, Y. J. Chem. Eng. Data 2009, 54, 1308.

19. Treszczanowicz, A.J.; Kiyohara, O.; Benson, G.C. J. Chem. Thermodyn. 1981, 13, 253.

20. Prolongo, M.G.; Mesagosa, R.M.; Fuentes, H.I.; Horta, A. J. Phys. Chem. 1984, 88, 163.

21. Jain, P.; Singh, M. J. Chem. Eng. Data 2004, 49, 1214.

22. Jyoti, N.N.; Mrityunjaya, I.A.; Tejraj, M.A. J. Chem. Eng. Data 2003, 48, 1489.

23. Reid, R.C.; Prausnitz, J.M.; Poling, B.E. The Properties of Gasesand Liquids, 4th ed., McGraw-Hill: New York; 1987.

24. Irving, J.B. Viscosities of Liquid Mixtures, NEL Reports 630 and 631; National Engineering Laboratory: East Kilbride, Glassgow; 1977.

25. Artigas, H.; Lafuente, C.; Lopez, M.C.; Royo, F.M.; Urieta, J.S. Z. Phys. Chem. 2001, 215, 933.

26. Gascon, I.; Martin, S.; Cea, P.; Lopez, M.C.; Royo, F.M. J. Solution Chem. 2002, 31, 905.

27. Kimura, F.; Treszczanowicz, A.; Halpin, C.; Benson, G. J. Chem. Thermodyn. 1983, 15, 503.

28. Pal, A.; Bhardwaj, R.K. Z. Phys. Chem. 2002, 216, 1033.

29. Ku, H.C.; Tu, C.H. J. Chem. Eng. Data 2005, 50, 608.

30. Alberto, A.; Eladio, P.; Eva, R.; Ana, S. J. Chem. Eng. Data 1999, 44, 291.

31. Glasstone, S. Textbook of Physical Chemistry; MacMillan: London; 1965.

32. Redlich, O.; Kister, A.T. Ind. Eng. Chem. 1948, 40, 345. 